Supplementary Information (SI)

\title{
Sustainable management of textile wastewater: A hybrid tight ultrafiltration/bipolar-membrane electrodialysis process for resource recovery and zero liquid discharge
}

\author{
Jiuyang Lin ${ }^{\mathrm{a}}$, Fang Lin ${ }^{\mathrm{a}}$, Xiangyu Chen ${ }^{\mathrm{a}}$, Wenyuan $\mathrm{Ye}^{\mathrm{b}, *}$, Xiaojuan $\mathrm{Li}^{\mathrm{a}}$, Huiming \\ Zeng $^{\mathrm{c}}$, Bart Van der Bruggen ${ }^{\mathrm{d}}$
}

Corresponding authors: ye0508@126.com (W. Ye)

${ }^{a}$ Fujian Provincial Engineering Research Center of Rural Waste Recycling Technology, School of Environment and Resources, Fuzhou University, 350116 Fuzhou, China

b Fujian Provincial Key Laboratory of Soil Environmental Health and Regulation, College of Resources and Environment, Fujian Agriculture and Forestry University, Fuzhou 350002, China

${ }^{\mathrm{c}}$ College of Chemical and Material Engineering, Quzhou University, Quzhou 324000, China

${ }^{\mathrm{d}}$ Department of Chemical Engineering, Process Engineering for Sustainable Systems (ProcESS), KU Leuven, Celestijnenlaan 200F, B-3001 Leuven, Belgium

Comprising 6 pages: 5 figures. 


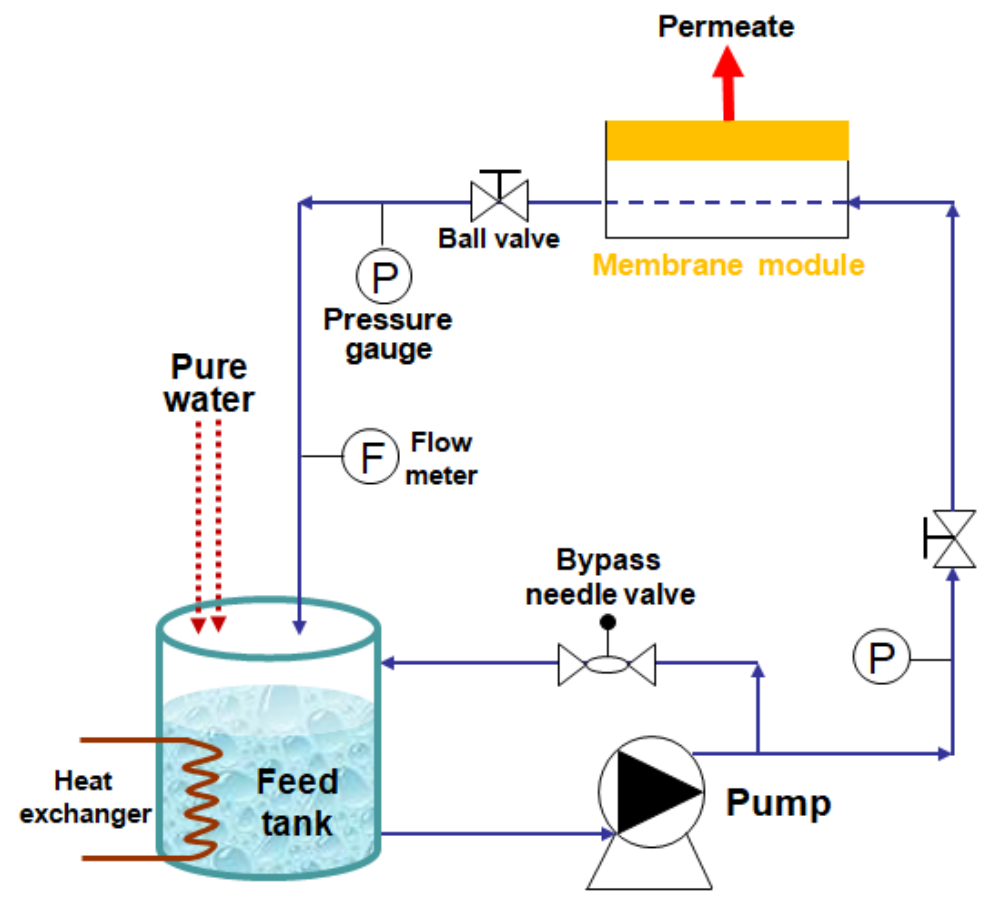

Figure S1. Schematic of integrated TUF-based diafiltration process for fractionation of dye/ $\mathrm{Na}_{2} \mathrm{SO}_{4}$ mixture. (Pre -concentration stage requires no water addition to reduce feed volume; diafiltration stage allows for addition of pure water to remove $\mathrm{Na}_{2} \mathrm{SO}_{4}$ from dye $/ \mathrm{Na}_{2} \mathrm{SO}_{4}$ mixtures) 

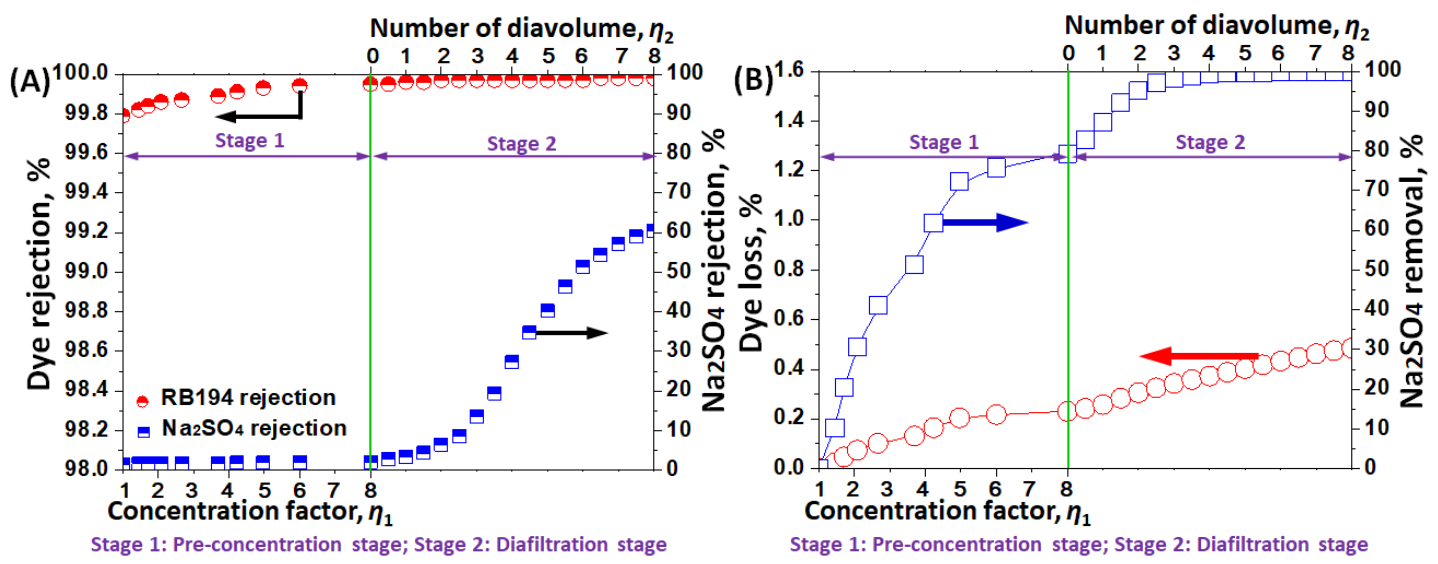

Figure S2. (A) Dye and $\mathrm{Na}_{2} \mathrm{SO}_{4}$ rejection and (B) dye loss and $\mathrm{Na}_{2} \mathrm{SO}_{4}$ removal during integrated TUF-based diafiltration for $\mathrm{RB} 194 / \mathrm{Na}_{2} \mathrm{SO}_{4}$ mixture. 


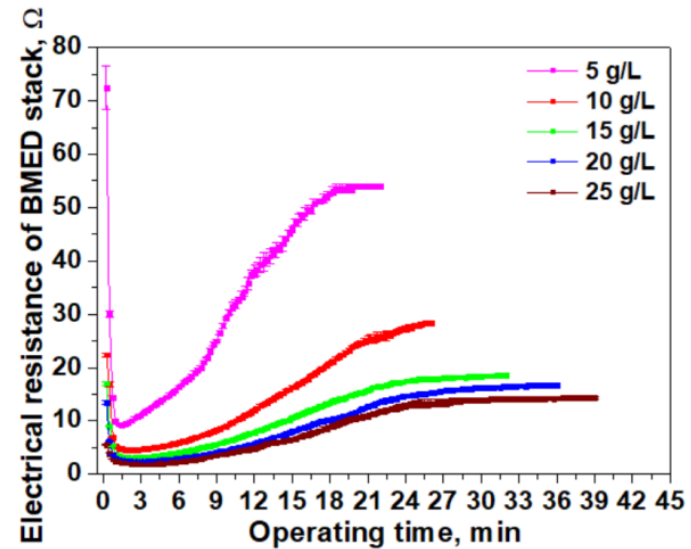

Figure S3. Evolution of electrical resistance of BMED stack when using various $\mathrm{Na}_{2} \mathrm{SO}_{4}$ solutions with different concentrations as feed with external $\mathrm{pH}$ control. 

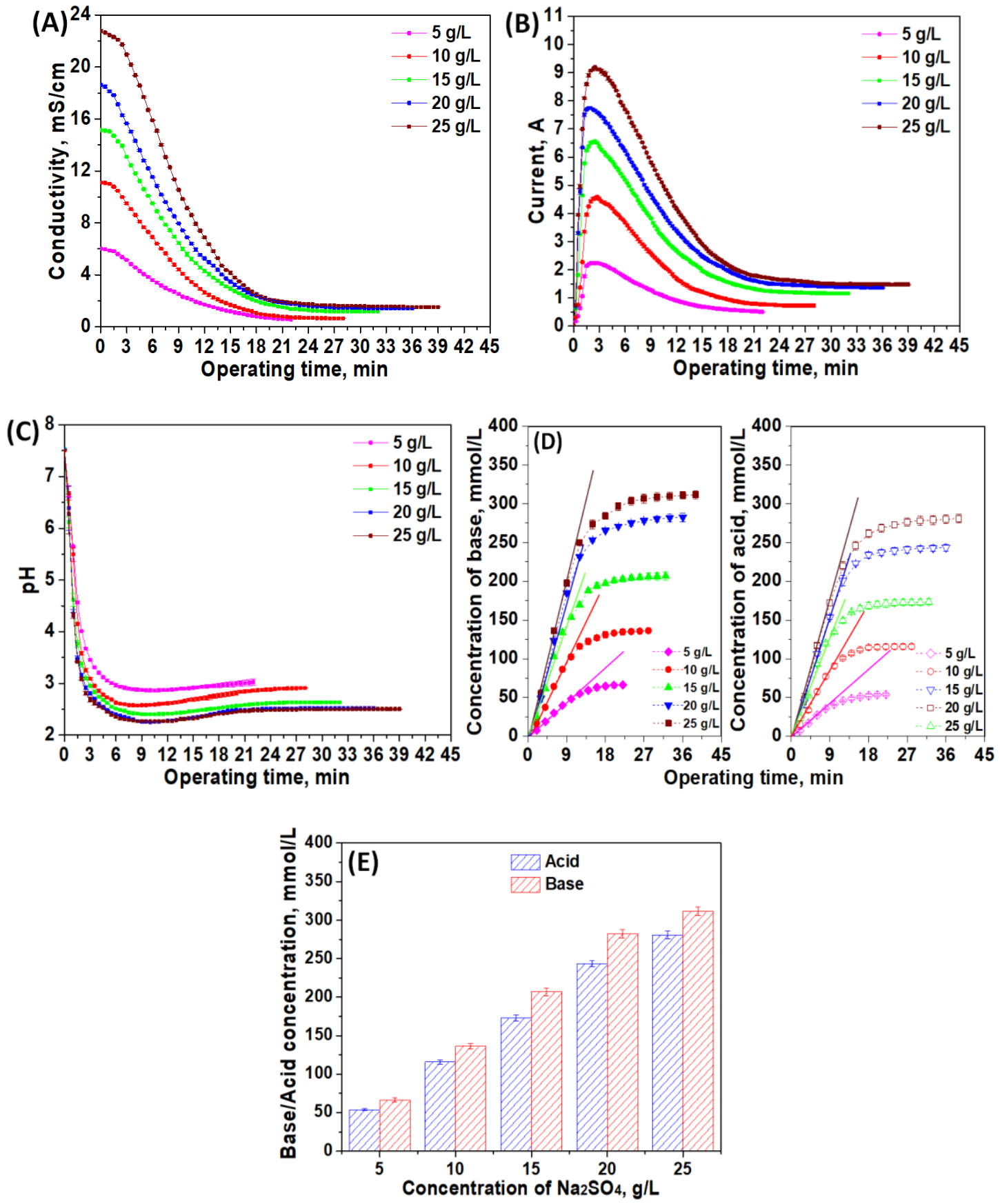

Figure S4. BMED performance in various $\mathrm{Na}_{2} \mathrm{SO}_{4}$ solutions without external $\mathrm{pH}$ control. (A) Evolution in conductivity of feed, (B) current across BMED stack, (C) feed $\mathrm{pH},(\mathrm{D})$ acid and base yield of BMED stack, and (E) final acid and base concentrations. 


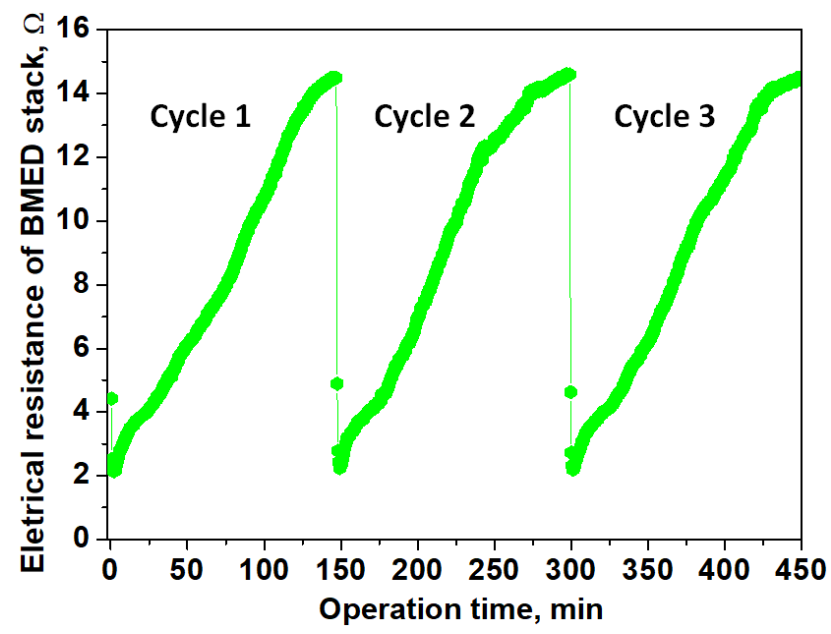

Figure S5. Evolution of electrical resistance of BMED stack when using TUFpermeate as feed at different cycles. 